\title{
Desenvolver o pensamento crítico em jardim de infância com e através de recursos digitais
}

\author{
Nídia Mesquita' (D); Diana Martins ${ }^{1}$ (D); Maria José Gamboa² (D) \\ ${ }^{1}$ Escola Superior de Educação e Ciências Sociais e Centro de Estudos Em Educação e Inovação (CI\&DEI); ${ }^{2}$ Instituto \\ Politécnico de Leiria, Portugal.
}

Resumo. O cenário de pandemia e de isolamento social atual desafia os educadores a reinventar modos de agir pedagógico potenciadores do desenvolvimento harmonioso da criança, especificamente através do desenvolvimento do seu pensamento crítico. Neste processo, reconhecidas as potencialidades pedagógicas das tecnologias e recursos digitais e a necessidade de criar ambientes de aprendizagem em rede, envolvendo a criança e a sua família, o educador de infância e a sociedade envolvente, pretende-se no âmbito deste artigo descrever e refletir sobre as implicações pedagógicas inerentes à criação e dinamização de uma experiência vivida com crianças de três e quatro anos, em educação pré-escolar, evidenciando as competências de pensamento crítico a desenvolver. Este estudo assume características investigativas que refletem sobre a ação pedagógica do educador, tendo em conta que se pretende relatar as opções tomadas para potenciar o desenvolvimento de competências de pensamento crítico através do uso de recursos digitais diversificados. O estudo inserido num paradigma de natureza qualitativa demonstrou a relevância do agir educativo reflexivo assente num processo de seleção informada e de construção de recursos educativos que potenciem o desenvolvimento do pensamento crítico da criança, através da exploração pedagógica de recursos disponíveis na esfera digital.

Palavras-chave: pensamento crítico; recursos digitais; agir pedagógico do educador.

Desarrollar el pensamiento crítico en la educación infantil con y por medio de los recursos digitales Resumen. El actual escenario de pandemia y aislamiento social desafía a los educadores a reinventar modos de acción pedagógica que potencien el desarrollo armónico de los niños y las niñas, en concreto a través del desarrollo de su pensamiento crítico. En este proceso, reconocido el potencial pedagógico de las tecnologías y recursos digitales, y la necesidad de crear entornos de aprendizaje en red, en los que se involucren al niño y su familia, al educador infantil y la sociedad circundante, se tiene por objeto describir y reflexionar sobre las implicaciones pedagógicas de crear y fomentar una experiencia vivida con niños y niñas de tres y cuatro años en la educación preescolar, evidenciando las competencias del pensamiento crítico que deben desarrollarse. Se asumen características de investigación científica que reflexionan sobre la acción pedagógica del educador, teniendo en cuenta que pretende describir las opciones adoptadas para potenciar el desarrollo de las competencias de pensamiento crítico mediante el uso de diversos recursos digitales. El estudio, que se incluye en un paradigma de carácter cualitativo, ha demostrado la importancia de una acción educativa reflexiva basada en un proceso de selección informada y construcción de recursos educativos que potencien el desarrollo del pensamiento crítico en los niños y las niñas, a través de la exploración pedagógica de los recursos disponibles en el ámbito digital

Palabras clave: pensamiento crítico; recursos digitales; acción pedagógica del educador.

Developing critical thinking in kindergarten with and through digital resources

Abstract. The current pandemic and social isolation scenario challenges educators to reinvent pedagogical ways of acting that enhance the child's harmonious development, using the development of their critical thinking. In this process, recognizing the pedagogical potential of digital technologies and resources and the need to create networked learning environments, involving children and their families, the kindergarten teacher and the surrounding society, this article aims to describe and reflect on the pedagogical implications inherent to the creation and dynamization of an experience lived with children of three and four years, in pre-school education, showing the critical thinking skills to be developed. This study assumes investigative characteristics that reflect on the educator's pedagogical action, bearing in mind that it is intended to report the options taken to enhance the development of critical thinking skills through the use of diversified digital resources.

The study inserted in a qualitative paradigm demonstrated the relevance of reflective educational action based on an informed selection process and the construction of educational resources that enhance the development of the child's critical thinking, through the pedagogical exploration of resources available in the digital sphere.

Keywords: critical thinking; digital resources; educator's pedagogical action. 


\section{Introdução}

Num cenário de pandemia mundial, 0 isolamento social desafia os educadores à reinvenção das suas práticas pedagógicas, colocando em foco a relevância de um agir educativo potenciado pelas tecnologias e pela produção e utilização pedagógica de recursos digitais.

Reconhecidas as potencialidades educativas e formativas inerentes à criação e mobilização pedagógica de recursos digitais, pretende-se, no âmbito deste artigo, considerar o agir do educador de infância enquanto agente do desenvolvimento de competências ao nível do pensamento crítico, através do uso das tecnologias digitais.

A convicção de que práticas potenciadoras do pensamento crítico abarcam propostas que levam ao questionamento, à reflexão e à discussão de ideias, constitui o ponto de partida do educador para pensar, em contexto de jardim de infância, o agir pedagógico como facilitador do desenvolvimento destas capacidades.

De forma a perceber como pode a criança ser apoiada, através de diferentes propostas elencadas em recursos digitais, pelo educador para desenvolver "(...) uma atitude exploratória e aberta ao mundo e para que construa a sua autonomia e iniciativa própria (...)" (Marchão, 2016, p. 49), construiu-se a seguinte questão, que servirá de ponto de partida para este estudo: De que forma o agir pedagógico do educador, potenciado pelo uso de recursos digitais, pode ser promotor do desenvolvimento do pensamento crítico das crianças?

A construção da resposta a esta pergunta de partida far-se-á no cruzamento do quadro teórico que a sustenta com a dinâmica educativa desenvolvida em contexto de jardim de infância.

\section{Discussão teórica}

\subsection{Pensamento crítico e recursos digitais no Jardim de Infância}

As abordagens socioconstrutivistas refletem uma imagem da criança ativa e participativa na sua aprendizagem. Num contexto de interações e relações, a criança é vista como um ser competente e participativo, assumindo um papel de relevo e de membro ativo no grupo social em que está inserido, uma vez que (...) lê o mundo e o interpreta, que constrói saber e cultura, que participa como pessoa e como cidadão na vida da família, da escola, da sociedade" (Oliveira-Formosinho, 2007, p. 27) 
Nesta linha de pensamento, "o reconhecimento da capacidade da criança para construir o seu desenvolvimento e aprendizagem supõe encará-la como sujeito e agente do processo educativo (...)" (Silva, Marques, Mata, \& Mota, 2016, p. 9), levando a que seja essencial a valorização das experiências de cada criança com vista ao desenvolvimento da mesma.

Neste sentido, importa referir que este papel advém dos direitos que a mesma possui, que segundo a Convenção sobre os Direitos da Criança e Protocolos Facultativos (UNICEF, 2019) são, entre outros: o direito de exprimir a opinião sobre variadas questões; o direito de exprimir pontos de vista ou ideias, obtendo informação sobre os mesmos; o acesso à informação e a diferentes materiais expressos através de diferentes fontes; a promoção do desenvolvimento da personalidade, dos dons e das aptidões e, por fim, o desenvolvimento da criança de forma holística com vista à formação de um papel ativo na sociedade.

Construir diariamente os direitos acima referidos implica uma atitude pedagógica por parte do educador voltada para a fomentação do desenvolvimento do pensamento crítico. Efetivamente, “(...) quando o educador assume a (...) escuta e permite interações ricas e estimulantes, (...) contribui para a construção de um pensamento mais elaborado e de índole mais crítico" (Marchão, 2016, p. 50).

Pensamento crítico pode assumir diversas definições, tendo em conta a finalidade da interpretação do mesmo. Neste sentido, partindo do facto de que este artigo emerge de um contexto de prática educativa, podemos defini-lo como "(...) uma forma de pensamento racional, reflexivo, focado naquilo em que se deve acreditar ou fazer" (Ennis, 1985, p.46). No entanto, este conceito não se esgota por esta única definição e segundo Guest (2000), o pensamento crítico abrange outras características, nomeadamente o caráter imaginativo e centrado na capacidade de criticar, analisar e contestar argumentos. Esta análise e contestação resulta da avaliação, caraterística inata no pensamento crítico, corroborado por Beyer (1984) ao afirmar que o pensamento crítico assume uma vertente avaliativa, onde se pensa criticamente acerca do processo que serve de desenvolvimento ao que se faz e aos produtos resultantes. A capacidade de pensar criticamente, através da reflexão, da crítica, da contestação e da avaliação é essencial para, como enunciado por Swartz e Perkins (1990), ser-se capaz de pensar e conhecer melhor o mundo envolvente e usar esse conhecimento para a resolução de problemas e a tomada de decisões. Ou característica do pensamento crítico é a ligação com a criatividade, que se assume como a base da formação deste, uma vez que, para a criança conseguir pensar criticamente sobre o que vê, ouve e sente necessita de ser criativa e singular (Lopes, Silva \& Morais, 2018). 
Neste sentido, a partir da escuta, dos interesses e experiências das crianças, o educador deve proporcionar momentos que potenciem o desenvolvimento de competências de escolha, tomada de decisões, de seleção de informação e "(...) de competências cognitivas, intelectuais, sociais, expressivas e comunicativas, não esquecendo que a criança precisa de criar, sentir e pensar em diferentes momentos, espaços de brincadeira e em outras atividades diversificadas e intencionais" (Marchão, 2016, p. 50).

As práticas potenciadoras do pensamento crítico devem abarcar propostas e rotinas que envolvam o constante questionamento e o espaço para as respostas. Segundo Marchão (2016), citando Ritchhart, Plamer, Church e Tishman (2006), "estas questões, colocadas de modo continuado, como uma rotina, levam a criança a pensar, a refletir e a discutir sobre as questões/ problemas e a partilhar com todo o grupo (...)" (p.51). Da mesma forma, estas práticas deverão ter em conta os vetores pedagógicos tempo, propostas, recursos e o questionamento, uma vez que, estes são "(...) indispensáveis para que [as crianças] evoluam na qualidade do seu pensamento e na afirmação da sua autonomia, na sua capacidade de decisão e de envolvimento no seu trajeto de aprendizagem" (Marchão, 2016, p. 51).

As competências enunciadas anteriormente são o ponto de partida para a construção da criança como sujeito preparado para a sociedade atual, tendo em conta a premissa de que a criança “(...) está inserida em uma sociedade globalizada e cercada de tecnologias (...), assumindo assim novas formas de brincar" (Francisco \& Silva, 2015, p. 284).

Neste sentido, é possível referir que as tecnologias, através do brincar, são uma forma de potenciar o desenvolvimento de competências de pensamento crítico nas crianças, usando como metodologia o questionamento e tendo como base os vetores pedagógicos referidos anteriormente.

Os contactos com as tecnologias, através do uso de recursos digitais, "(...) são um processo rico na construção de múltiplas aprendizagens" (Teixeira, 2014 , p. 20), que privilegiam o papel ativo e participativo das mesmas. Da mesma forma, "as crianças exploram, pesquisam e manuseiam [estes recursos] sem receios, nem limitações" (Teixeira, 2014, p. 20) permitindo que as mesmas desenvolvam capacidades ao nível intelectual, da linguagem, memória e outras. Por outro lado, a sua utilização permite o encorajamento e a utilização da imaginação; orienta para o sucesso; atribui às crianças o papel ativo, levando ao uso de relações, intuições, tomada de decisões e escolhas; permite a resolução de problemas, leva à cooperação e valoriza a diversidade étnica e cultural (Amante, 2007). 
Nesta ordem de ideias, o educador assume um papel preponderante na introdução das tecnologias na sala de jardim de infância, uma vez que, deve "saber o que fazer, quando, como e para quê [sendo] (...) aspetos a considerar por cada docente, no momento que precede a aplicação dos recursos educativos digitais, em qualquer contexto de sala de aula/atividades" (Teixeira, 2014, p. 20). Ponte (2002b) corrobora o enunciado ao afirmar que “(...) não basta ser capaz de integrar pontualmente as TIC na prática Pedagógica - é necessário ter uma visão global do papel que estas tecnologias podem desempenhar em todo o processo educativo e da respectiva fundamentação pedagógica" (p.21).

Neste sentido, as propostas elencadas nos recursos digitais deverão ter como premissa a ideia da criação de experiências diversificadas para o desenvolvimento do pensamento crítico, colaborando no processo de aprendizagem das crianças e permitindo que estas sejam seres capazes de resolver problemas, de forma racional e criticamente adequada (Vieira, Tenreiro-Vieira \& Martins, 2011).

Da mesma forma, estas propostas devem ser recheadas de momentos potenciadores do lúdico e da brincadeira, uma vez que, "É por meio da brincadeira que a criança se constitui sujeito, interage com o meio e com o outro; dessa forma, a criança se desenvolve e constrói sua identidade" (Francisco \& Silva, 2015, p. 283).

\section{Metodologia}

No âmbito das propostas construídas nas práticas pedagógicas em jardim de infância e num contexto de aprofundamento e reflexão acerca do agir pedagógico do educador, através das potencialidades de diferentes ferramentas digitais, para o desenvolvimento de competências de pensamento crítico nas crianças, considerou-se pertinente relatar reflexivamente a experiência vivida com crianças de três e quatro anos de idade e evidenciar as competências de pensamento crítico a desenvolver. Tomou-se como ponto de partida, para além do contexto vivido durante o isolamento social e a necessidade de atuar pedagogicamente à distância, a seguinte questão: De que forma o agir pedagógico do educador, potenciado pelo uso de recursos digitais, pode ser promotor do desenvolvimento do pensamento crítico das crianças?

O paradigma de investigação que serviu de base para este estudo é de natureza qualitativa, de carácter descritivo (Fortin, 1999). Assim sendo, usou-se o estudo de caso (Amado, 2014). O caso em questão trata-se de um trabalho desenvolvido no contexto descrito, e assume características inves- 
tigativas que refletem sobre a ação pedagógica do educador (Ponte, 2002a), tendo em conta que se pretende relatar as opções tomadas para potenciar o desenvolvimento de competências de pensamento crítico através do uso de recursos digitais diversificados.

A recolha de dados é feita através de observação direta e participante, tendo como registo o diário de bordo. Após a formulação de cada proposta, foi relatada a descrição da mesma e acrescentada uma reflexão didática acerca das opções tomadas e das respetivas potencialidades para a promoção do pensamento crítico.

Os dados foram tratados através da análise de conteúdo (Dias, 2009), tendo como objetivo a interpretação dos mesmos.

\section{Descrição e implementação das propostas}

Num cenário de pandemia mundial, em que o isolamento levou à reinvenção das práticas educativas, surgiu a necessidade de construir propostas que promovessem o pensamento crítico nas crianças para serem usufruídas em casa. "Este cenário tem oferecido uma oportunidade de experimentação de novos modelos pedagógicos e de novas formas de utilizar os tempos de aprendizagem. Temos assistido a tempos difíceis de adaptação e inovação, exigidos pelas dinâmicas de ensino aprendizagem-avaliação deste novo "normal" (...)" (Verdasca et al., 2020, p. 12) que incluem o uso das tecnologias e dos recursos que pais e crianças possuem em casa.

A partir da necessidade de trabalhar através das tecnologias, de forma a "Otimizar a utilização das plataformas de ensino à distância bem como recursos educativos digitais disponíveis online e eventualmente desenvolver novas plataformas (Verdasca et al., 2020, p. 13) surgiu a construção de propostas que tiveram por base o uso de diversos recursos digitais. Estas foram implementadas ao longo de três semanas, a cada três dias, usando como meio de comunicação a plataforma Childdiary.

A base do trabalho a desenvolver com as crianças, nesta nova modalidade de agir, foi assente em rotinas, de modo a promover segurança e tranquilidade. Da mesma forma, este trabalho foi feito com e a partir dos pais, mas nunca deixando de lado a autonomia das crianças. Neste sentido, as propostas foram elaboradas a partir do brincar, atividade natural e espontânea da criança, e através da criação de oportunidades interessantes e desafiadoras de aprendizagem (DGE, 2019-2020) 
As propostas foram lançadas aos pais, diariamente até às dez horas da manhã, e pensadas para serem usufruídas pelas famílias, ou na impossibilidade, só pelas crianças. Da mesma forma foram idealizadas para terem uma curta duração, envolverem o uso de materiais do quotidiano e permitir que as crianças explorassem de uma forma integradora as várias áreas de conteúdo referidas nas Orientações Curriculares, tendo como partida as Cem Linguagens das crianças enunciadas por Loris Malaguzzi (Edwards, Gandini \& Forman, 2012).

Por outro lado, de forma a potenciar a participação ativa e o desenvolvimento do pensamento crítico, estas propostas tinham inerentes a possibilidade de a criança efetuar escolhas, de tomar decisões, de selecionar informação e de se desenvolver de forma holística, através da escolha, do criar, do sentir e do pensar.

Neste sentido, tendo como base a inspiração na abordagem Reggio Emilia (Lino, 2013), a agência das crianças e os seus interesses, as propostas tiveram como indutor os animais. Este ponto de partida nasceu do período de observação, da escuta ativa e consequente análise dos registos de observação e da necessidade de colocar os animais em relevo nas propostas dirigidas às crianças, como meio de motivação e necessidade de alargamento das experiências das crianças.

A partir desta observação, tornou-se pertinente transpor estes interesses para as propostas desenvolvidas para o meio familiar e cativar as crianças de uma forma lúdica e mágica, usando os recursos digitais como meios de promoção do conhecimento e da exploração de diferentes animais. Neste sentido, foram elaboradas cinco propostas com diferentes animais, recorrendo a diferentes recursos digitais. Na tabela 1 esquematizam-se as diferentes propostas.

Tabela 1. Tabela esquemática das diferentes propostas sugeridas

\begin{tabular}{lll}
\multicolumn{1}{c}{ Proposta } & \multicolumn{1}{c}{ Indutor } & \multicolumn{1}{c}{ Recurso Digital } \\
\hline "Piper, o passarinho curioso" & Ave & $\begin{array}{l}\text { "Pipper" - Curta Metragem do } \\
\text { Plano Nacional de Cinema para } \\
\text { o Pré-Escolar }\end{array}$ \\
& & $\begin{array}{l}\text { Art-Builder } \\
\text { "O nosso Piper...?" }\end{array}$ \\
"Faces Opostas" & Ave & Site da Fundação Serralves \\
"Somos Curiosos" & Insetos & Rádio Miúdos \\
"Yoga" & Insetos & Programa da RTP "Yoga para as \\
& Gato, vaca, tigre e ave & \\
\hline
\end{tabular}

Fonte: elaboração própria.

De seguida, apresentamos uma descrição mais detalhada de cada uma das propostas, de forma a dar a conhecer o trabalho realizado. 
A proposta Piper, o passarinho curioso, consistia na visualização de uma curta metragem com o título Piper de Alan Barillaro, que consta no Plano Nacional de Cinema na Direção Geral de Educação Portuguesa. A proposta foi apresentada às crianças em forma de convite, sendo que estas eram motivadas a usufruírem da visualização do vídeo de uma forma descontraída e lúdica, permitindo o envolvimento das famílias. Assim sendo, a nossa sugestão usou como recurso as seguintes indicações que constam no diário de bordo:

\section{Bom dia amigos!!}

Esperamos que se encontrem bem.

Estão preparados para mais brincadeiras? Hoje trazemos um filme, do plano nacional de cinema, para verem sozinhos ou acompanhados. Mas têm de ver com muita atenção!

Terão de descobrir:

- quem é o Piper?

- o que o Piper vai fazer?

- onde é que está.

Vocês irão precisar destas informações para as próximas brincadeiras por isso gravem as vossas respostas usando o telemóvel do pai ou da mãe e depois enviem-nos. Vamos falar sobre isto na próxima reunião do zoom.

Não se esqueçam, façam pipocas e divirtam-se!!!

A escolha deste recurso digital assentou na importância da ligação da arte com a educação, tendo como objetivo "Ampliar (...) o leque de possibilidades de cruzamento e integração de conteúdos entre disciplinas das diversas áreas científicas do currículo, no sentido de proporcionar experiências culturais enriquecedoras aos alunos e às comunidades educativas" (DGE, 2019-2020, p. 3). Da mesma forma, esta proposta visava a resposta às seguintes questões orientadoras do processo de compreensão: quem é o Piper?; o que o Piper vai fazer? e onde está o Piper?. Estas questões, didaticamente, assumem uma importância ao nível da linguagem e da literacia, uma vez que, era nosso intuito potenciar uma experiência que, para além da compreensão da história, dava oportunidade aos pais para uma participação mais efetiva, criando um momento que permitisse o uso da linguagem. Esta ideia partiu da premissa de que "(...) proporcionar ocasiões para as crianças conversarem é uma das partes mais importantes da abordagem da aprendizagem pela acção, e não uma perda de tempo ou distração relativamente a coisas alegadamente mais importantes" (Hohmann \& Weikart, 2009, p. 538). Da mesma forma, estas questões serviram como ponto de partida para a reflexão e análise da informação acerca das características do Piper, levando ao desenvolvimento do pensamento crítico e ao debate de ideias e opiniões na conversa em grande grupo na aplicação ZOOM. Assim, como enunciado por Guest (2000), esta proposta permitia que as crianças utilizassem a imaginação e a criatividade para analisar e argumentar sobre o comportamento do Piper. 
A segunda proposta, 0 nosso Piper..., tinha como desafio a recriação do Piper através da utilização da ferramenta digital Art Builder. A aplicação enunciada permite a criação digital de composições visuais com colagens (de materiais como tecidos, botões, penas entre outros). Esta foi apresentada de forma a cativar as crianças para o uso do computador através das artes visuais, usando como recurso as seguintes indicações que constam no diário de bordo:

Bom dia, amigos!

Estão bem-dispostos? Hoje vamos precisar de um computador para trabalhar como a mãe e o pai fazem no dia a dia. Querem? Peçam ajuda ao pai ou à mãe e mãos à obra!!

Lembram-se do Piper? O passarinho do filme que vimos ontem?

Era muito engraçado, não era? Mas bastante curioso...

Hoje o desafio é recriarmos o Piper usando um programa que permite a criação de composições visuais com colagens, de materiais diversos. Não perceberam? Não faz mal, depois de experimentarem vão perceber tudo!

Não se esqueçam de nos enviar o resultado final!

Já agora, lanço-te outra questão: gostas da ideia de usar esta aplicação? Se pudesses fazias o Pipper usando outro recurso? Ou de outra forma? Pensa sobre isso e depois falamos na próxima reunião do ZOOM.

Nota: Amigos, se não tiverem como ir ao computador façam o Piper em desenho numa folha branca, com lápis ou canetas. Podem ainda acrescentar outros materiais: acordem a senhora imaginação!

Divirtam-se, amigos!

Esta proposta nasceu da premissa de que os computadores permitem uma aprendizagem pela ação, e que "(...) fazem hoje parte da vida de todas as crianças, tanto em momentos de lazer (...), como no seu quotidiano (...)" (Silva et al, 2016, p. 93). Assim sendo, a aplicação Art Builder foi vista como um meio para as crianças utilizarem as funcionalidades básicas da ferramenta, recorrerem à memória visual das características do Piper, proporem-se a novos desafios promotores de aprendizagens e revelarem originalidade nas suas criações gráficas. Por fim, colocou-se como base desta proposta as artes visuais, uma vez que, "As diferentes linguagens artísticas (...) são meios de enriquecer as possibilidades de expressão e comunicação das crianças" (Silva et al., 2016, p. 47)". Da mesma forma, através desta proposta as crianças tinham a possibilidade de desenvolver o pensamento crítico através da avaliação do trabalho realizado por elas no desenrolar da construção do seu Piper, assim como, a tomada de decisão em relação ao trabalho a desenvolver ou quanto à possibilidade de o desenvolver de outra forma que não a sugerida. (Swartz e Perkins, 1990) Estas competências seriam desenvolvidas no diálogo em grande grupo na reunião através da aplicação Zoom. 
Através da proposta Faces Opostas, as crianças eram convidadas a conhecer o site da Fundação Serralves. Esta Fundação tem como objetivo principal a promoção de "(...) programa de atividades, fruto de um trabalho integrado entre as Artes e o Ambiente, na qual a partilha e a experiência, são o mote para a promoção da criatividade, da reflexão e da ação" (Silva, Lapa, Cruz \& Tavares, 2019-2020, p. 3). Esta foi apresentada usando como recurso as seguintes indicações que constam no diário de bordo:

\section{Bom dia amigos!!}

Como se sentem hoje? Felizes? Esperamos que o fim de semana tenha sido bom.

Hoje trazemos um desafio diferente. Já ouviram falar da Fundação Serralves? É um lugar que dá valor às artes, ao ambiente e à sociedade. A Fundação Serralves tem um site com muitas atividades para as crianças e pensámos que iriam gostar de realizar uma delas.

Vão ao link que vos vamos dar e entrem na página da internet da Fundação. Escolham um dos insetos, imprimam e desenhem a parte que falta. Podem usar canetas, lápis de cor, lápis de cera ou outro material... escolham. Se quiserem podem escrever o nome do inseto que escolheram, peçam ajuda aos pais ou tentem sozinhos.

Se não conseguirem imprimir, não há problema. Vão à procura de uma revista ou de um panfleto que tenha insetos e usem. Cortem a imagem, depois cortem a imagem ao meio, colem essa parte numa folha branca e desenhem a parte que falta.

Não se esqueçam: usem a Sra. Imaginação e tirem fotografia aos vossos trabalhos. Queremos muito ver!!!!

Divirtam-se.

Pretendeu-se que as crianças aderissem aos desafios das atividades delineadas pela equipa pedagógica da fundação, que tinha como objetivo o desenho da simetria dos animais disponibilizados, e a escreverem o nome do animal escolhido. A decisão de escolher o site da Fundação Serralves nasceu do facto de este possuir um "(...) programa de atividades, fruto de um trabalho integrado entre as Artes e o Ambiente, na qual a partilha e a experiência, são o mote para a promoção da criatividade, da reflexão e da ação" (Silva, Lapa, Cruz \& Tavares, 2019-2020, p. 3), caraterísticas fundamentais na abordagem Reggio Emilia (Lino, 2013) e na definição da imagem da criança, para Loris Mallaguzi (Lino, 2013).

Na linha deste pensamento, a escolha da atividade Faces Opostas resultou da necessidade de aliar a área de expressão e comunicação e a área de conhecimento do mundo de forma integrada. Desta forma, ao nível da matemática, partindo da premissa de que as crianças são sensíveis às formas e à distinção das mesmas e que “(...) este processo desenvolve-se a partir da observação e manipulação de objetos com diversas formas geométricas, 
de modo (...) a aprender a diferenciar, nomear e identificar as propriedades (...)" (Silva, Marques, Mata \& Rosa, 2016, p. 80) optámos por fornecer a possibilidade de escolher um dos insetos (que contêm formas geométricas no seu revestimento) e a desenharem a parte que falta. Da mesma forma, esta proposta potencia o pensamento crítico através do desenvolvimento da capacidade de resolver problemas, onde as crianças são incentivadas a escolherem outra fonte para recolher a imagem que seria alvo de simetria. (Swartz e Perkins, 1990)

A proposta Somos Curiosos foi contruída tendo como base a Rádio Miúdos, rádio portuguesa. Através de um contacto feito à Radio Miúdos, percebeu-se que era possível publicar a gravação de uma investigação, feita por cada criança sobre o animal escolhido na proposta anterior. Assim sendo, as crianças foram convidadas a investigar e a recolher informações sobre os animais que escolheram, com vista à gravação de um podcast. Esta foi apresentada usando como recurso as seguintes indicações que constam no diário de bordo:

Olá amigos! Bom dia!

Prontos para mais um desafio?

Hoje trazemos de volta a "Rádio Miúdos" e uma grande novidade. Ao contactar a Rádio Miúdos percebemos que existe a possibilidade de publicarmos uma gravação online.

Pensámos que seria uma boa ideia fazerem uma pesquisa sobre os insetos que desenharam ontem e falarem sobre o que descobriram. Para tal, peçam ajuda aos pais e gravem uma faixa de som com as vossas descobertas.

Enviem-nos e nós encaminhamos para a Rádio Miúdos. As vossas gravações serão publicadas no programa "Só para curiosos".

Seria fantástico conseguir divulgar o que aprendemos e o trabalho que realizámos com os restantes ouvintes da rádio.

Divirtam-se, pequenos locutores!!!!!

Nota para os pais: Para as gravações das crianças serem publicadas necessitamos de uma autorização por escrito. Enviamos em anexo.

Investir no contacto com a rádio partiu da premissa de que:

(... ) a sua introdução na educação traz vantagens como o incentivo à leitura e produção de textos para as emissões, o desenvolvimento da oralidade e da narrativa, a possibilidade de pesquisa e capacidade de seleção, o uso informado de novas tecnologias, o fomento de uma capacidade comunicativa e de reflexão crítica e a criação de uma nova relação entre aluno, professor e comunidade educativa baseada na troca de informação e conhecimento (Junior e Coutinho, 2008, pp. 104-105). 
Esta proposta tinha como potencialidades para o desenvolvimento do pensamento crítico a seleção da informação a pesquisar, a reflexão acerca da informação a utilizar e a tomada de decisão sobre a forma de apresentar a informação no podcast, contribuindo assim para o desenvolvimento do pensamento crítico, usando características enunciadas pelos autores de referência nesta temática (Beyer, 1984; Swartz e Perkins, 1990; Guest, 2000).

Por fim, a proposta Yoga consistia na realização de uma atividade motora através do programa Yoga para crianças, do canal televisivo RTP2. Com esta proposta as crianças eram convidadas a movimentarem o corpo usando as indicações da personagem principal do episódio. Esta foi apresentada usando como recurso as seguintes indicações que constam no diário de bordo:

Bom dia amigos!

Dormiram bem?

Como temos andado a falar de animais, lembrámo-nos que seria uma boa ideia ver uma aula de yoga orientada por um gato, que nos vai ajudar a libertar o stress. Nada melhor que esticar o corpo com a ajuda do yoga.

O desafio de hoje é imitarem as posições de uma aula de yoga da RTP2. Para tal peçam ajuda aos pais e acedam a este link: https://www.rtp.pt/ play/zigzag/p7107/e472394/ioga-para-criancas.

Oiçam, vejam e imitem.

Já agora, outra sugestão: o que achas desta ideia de fazeres movimentos a olhar para a televisão ou o computador? Gostas? Porquê? Ou gostas mais das nossas atividades na sala? Grava a tua opinião e envia-me, quero muito conhecer os teus argumentos.

Se quiserem gravem ou tirem uma fotografia para nós vermos.

Divirtam-se amigos!!!!

Apostou-se na realização desta proposta pois é um meio acessível a todas as famílias, através das operadoras de televisão, como através da internet e do site da estação de televisão; é também um meio para as crianças efetuarem exercícios de alongamentos e relaxamento num espaço de casa, permitindo assim tentar colmatar a ausência da expressão motora ou das brincadeiras ao ar livre que a instituição proporcionava às mesmas. Com estes exercícios a criança consegue lidar mais facilmente com a falta de estímulos mas também o simples facto de praticar alguma atividade física, “(...) favorece também o crescimento, a forma, a força e a elasticidade corporal e a libertação de endorfinas a nível cerebral [facilitando também] o relaxamento" (Cordeiro, 2015, p. 434). Da mesma forma, esta proposta potenciava o desenvolvimento do pensamento crítico ao dar lugar à voz da criança no que concerne à sua opinião acerca da proposta e das diferenças de esta ser realizada em casa, através da televisão ou do computador, ou na sala com o restante grupo de crianças (Guest, 2000). 
Ao nível das aprendizagens, como enunciado anteriormente, foi tido em conta a importância de promover propostas integradoras do currículo. Neste sentido, a criação das propostas educativas e os desafios que estas integravam visaram a construção de ambientes de participação facilitadores de aprendizagens nas diferentes áreas do saber, no entanto, achamos importante realçar aquelas que vão ao encontro do desenvolvimento do pensamento crítico, das quais destacamos: reconhecimento, valorização, utilização e análise das tecnologias e das diversas ferramentas digitais apresentadas; desenvolvimento de competências essenciais para a resolução de problemas; desenvolvimento de competências que levem ao uso da imaginação, criatividade e originalidade; promoção da curiosidade pelo conhecimento do mundo; desenvolvimento da capacidade de fazer escolhas e de lidar com as mesmas; desenvolvimento da capacidade crítica, entre outras (Silva et al., 2016).

\section{Aprendizagens: da implementação ao pensamento crítico}

As propostas efetuadas ao longo deste período visaram integrar as várias áreas do currículo e as aprendizagens especificas do pensamento crítico, com a finalidade de desenvolver a motivação e o interesse das crianças.

Neste sentido, de forma a dar voz ao desenvolvimento das propostas, torna-se pertinente fazer um resumo das aprendizagens das crianças. Por uma economia de espaço e palavras, assim como, por respeito à privacidade dos dados das crianças e do trabalho desenvolvido pelas mesmas, iremos explorar apenas a proposta: 0 nosso Piper..., que tinha como desafio a recriação do Piper através da utilização da ferramenta digital Art Builder (Silva et al., 2016).

Assim sendo, começando pelo reconhecimento, valorização, utilização e análise das tecnologias e da ferramenta digital apresentada, foi possível perceber que as crianças reconheceram imediatamente o teor da proposta por ser desenvolvida no computador; conseguiram explorar os diferentes comandos da ferramenta digital através de ligações entre o que conheciam e o que estavam a ver e demonstraram a sua opinião em relação à funcionalidade da ferramenta.

Em relação ao desenvolvimento de competências essenciais para a resolução de problemas, as crianças conseguiram, através da experimentação e procura na ferramenta, decifrar os comandos mesmo sem saber ler (Silva et al., 2016; Leopoldina et al., 2014). 
Em relação ao desenvolvimento de competências que levam ao uso da imaginação, criatividade e originalidade e ao desenvolvimento da capacidade de fazer escolhas e de lidar com as mesmas, as crianças conseguiram produzir singulares representações do Piper, usando a memória, a capacidade de julgamento, a autoconfiança em relação ao que estavam a fazer, a resiliência e a sensibilidade estética (Morais, 2004).

Em relação à promoção da curiosidade pelo conhecimento do mundo, as crianças conseguiram nas representações colocar as características físicas principais que constituem uma ave, assim como alguns elementos do ambiente marinho em que esta se encontra. Da mesma forma, foi possível perceber nas crianças a capacidade de interpretação da curta metragem (Silva et al., 2016; Martins, 2002).

Por fim, em relação desenvolvimento da capacidade crítica, as crianças conseguiram avaliar o trabalho realizado no desenrolar da construção do seu Piper, assim como, tomar decisões em relação ao trabalho a desenvolver ou quanto à possibilidade de o desenvolver de outra forma que não a sugerida. (Swartz e Perkins, 1990).

\section{Síntese conclusiva}

A questão de partida que serviu de base a este estudo permite concluir que, através da construção de propostas que envolvam o questionamento, a reflexão e a discussão de ideias, colocando os recursos digitais, tão presentes no cotidiano das crianças, como base para o seu envolvimento, o educador pode auxiliar as crianças no desenvolvimento do pensamento crítico e na aquisição de aprendizagens holísticas das diferentes áreas do saber.

De facto, como enunciado por Marchão (2016), as propostas vividas pelas crianças devem ser recheadas de questões que as levam a pensar sobre o que estão a fazer e devem permitir o debate de ideias e a capacidade de pensar criticamente. Os recursos digitais são uma forte aposta para a promoção destas mesmas capacidades, uma vez que implicam o encorajamento e a utilização da imaginação; orientam para o sucesso; atribuem às crianças o papel ativo, levando ao uso de reações, intuições, tomada de decisões e escolhas; permitam a resolução de problemas, levem à cooperação e valorizem a diversidade étnica e cultural (Amante, 2007).

A apresentação e reflexão das propostas educativas, que atrás enunciámos, e as aprendizagens a promover são um exemplo enriquecedor das práticas a adotar pelo educador de infância. Através delas foi possível 
perceber a ligação, num ciclo de ação pedagógica, entre as dinâmicas e fundamentos da abordagem que servem de base a esta experiência, a construção das propostas a partir da escuta ativa e dos interesses das crianças, as aprendizagens integradoras do currículo a promover e as competências de pensamento crítico a desenvolver.

Da mesma forma, reconhecendo a omnipresença do digital na vida das crianças e dos seus educadores, e as características lúdicas das propostas apresentadas, destacamos a importância de o educador refletir sobre as potencialidades dos recursos digitais disponíveis e a sua exploração pedagógica integrada, num paradigma de ludicidade, em ordem à participação e implicação da criança nas propostas educativas e ao desenvolvimento do seu pensamento crítico.

\section{Referências}

Amado, J. (2014). Manual de Investigação qualitativa em Educação. Coimbra: Imprensa da Universidade de Coimbra.

Amante, L. (2007). As TIC nas escola e no Jardim de Infância. SÍSIFO: Revista de Ciências da Educação, 3, 51-64.

Beyer, B.K. (1984). Improving thinking skills: Defining the problem. The Phi Delta Kappan, 65(7), 486-490.

Cordeiro, M. (2015). O livro da criança. Lisboa: A esfera dos livros.

Edwards, C., Gandini, L. \& Forman, G. (Eds.). (2012). The Hundred Languages of Children: The Reggio Emilia Experience in Transformation (3rd ed.). Santa Barbara: Praeger.

Ennis, R. (1985). A logical basis for measuring critical thinking skills. Educational Leadership, 43(2), 44-48. Acessível em https://bit.ly/2OH98cz

Dias, M.O. (2009). O Vocabulário do Desenho da Investigação. Viseu: Psico \& Soma.

DGE (Abril de 2019-2020). Modelo de planificação de atividades para a Educação Pré-Escolar. Ministério da Educação/Direção-Geral da Educação (DGE). Obtido de Apoio às Escolas.

Fortin, M.-F. (1999). O processo de Investigação: da concepção à realização. Loures: Lusociência, Edições Técnicas e Científicas.

Francisco, D.J. \& Silva, A.P. (2015). Criança e apropriação tecnológica: um estudo de caso mediado pelo uso do computador e do tablet. Holos, 6(31), 277-296.

Guest, K. (2000). Introducing Critical Thinking to 'Nonstandard' Entry Students. The Use of a Catalyst to Spark Debate. Teaching in Higher Education, 5(3), 289-300.

Hohmann, M. \& Weikart, D. P. (2009). Educar a criança. Lisboa: Fundação Calouste Gulbenkian.

Junior, J. \& Coutinho, C. (2008). Rádio e Tv na Web: vantagens pedagógicas e dinâmicas na utilização em contexto educativo. TEIAS,17, 101-109. Acessível em https://bit. ly/3qtwSTg 
Leopoldina, F., Ribeiro, I., Baptista, A., Costa, H., Cadime, I., Ríos, I., . . Santos, S. (2014). Falar, Ler e Escrever: Propostas Integradoras para Jardim de Infância. Lisboa: Santillana.

Lino, D. (2013). O modelo pedagógico de reggio emilia. In Oliveira-Formosinho, J. (Org.), Modelos curriculares para a educação de infância: construindo uma praxis de participação. Porto: Porto Editora, pp. 109-140.

Lopes, J., Silva. H. \& Morais. E. (2018). Teste de pensamento crítico para estudantes dos ensinos básico e secundário. Revista de estudos e investigación en psicologia e educación, 5(2), 82-91.

Marchão, A. d. (2016). Ativar a construção do pensamento crítico desde o jardim-de-infância. Revista Lusófona de Educação, 32, 47-58.

Martins, I. P. (2002). Educação em ciência e educação em ciências. Aveiro: Universidade de Aveiro.

Morais, M. d. (2004). O Educador e a Personalidade Criativa: Algumas considerações. Criatividade e Educação, 5, 33-45.

Oliveira-Formosinho, J. (2007). Pedagogia(s) da infância: reconstruindo uma praxis de participação. Em J. Oliveira-Formosinho e T. Kishimoto, Pedagogia(s) da infância. Dialogando com o passado. Construindo o futuro (pp. 13-36). São Paulo: Artmed.

Ponte, J. P. (2002a). Investigar a nossa própria prática. Em GTI (Org), Reflectir e investigar sobre a prática profissional. (pp. 5-28). Lisboa: APM.

Ponte, J. P. (2002b). As TIC no início da escolaridade - Perspectivas para a formação inicial de professores. Em J. Ponte (org.) A formação para a integração da TIC na Educação Pré-Escolar e no $1 .{ }^{\circ}$ Ciclo do Ensino Básico (pp.19-26). Porto: Porto Editora

Silva, A., Lapa, C., Cruz, D. \& Tavares, M. (2019-2020). Programas Educativos Serralves. Obtido de Serralves: https://bit.ly/3qEvtJR

Silva, I. L., Marques, L., Mata, L. \& Mota, M. (2016). Orientações Curriculares para a Educação Pré-Escolar. Lisboa: Ministério da Educação/Direção-Geral da Educação (DGE).

Swartz, R. \& Perkins, D. (1990). Teaching thinking: Issues \& approaches. Pacific Grove, CA: Critical Thinking Press \& Software.

Teixeira, S. d. (2014). Recursos digitais no Jardim de Infância: A narrativa digital para pormover multiliteracias. Braga: Universidade do Minho.

Swartz, R. \& Perkins, D. (1990). Teaching thinking: Issues \& approaches. Pacific Grove, CA: Critical Thinking Press \& Software.

UNICEF (2019). Convenção sobre os Direitos da Criança e Protocolos Facultativos. Comité Português para a UNICEF. Acessível em https://bit.ly/36LajBR.

Verdasca, J., Neves, A. M., Fonseca, H., Fateixa, J. A., Procópio, M. \& Magro-C, T. (2020). A Escola em Tempos de COVID19: reflexões sobre o novo "normal" e perspetivas para o futuro. Norte 2020 Educação para todos, 13, 11-14.

Vieira, R. M., Tenreiro-Vieira, C. \& Martins, I. (2011). A educação em ciências com orientação CTS. Porto: Areal Editores. 